\title{
Cross-Linked Density Determination of Natural Rubber Compounds by Different Analytical Techniques
}

\author{
Carlos Toshiyuki Hiranobe ${ }^{a}(1)$, Gabriel Deltrejo Ribeiro ${ }^{a}$, Giovanni Barrera Torres ${ }^{b}$, \\ Elton Aparecido Prado dos Reis ${ }^{c}$, Flávio Camargo Cabrera ${ }^{d}$, Aldo Eloizo Job ${ }^{e}$, \\ Leonardo Lataro Paim ${ }^{a}$, Renivaldo José dos Santos * (1) \\ ${ }^{a}$ Universidade Estadual Paulista (UNESP), Engenharia de Energia, Campus de Rosana, Avenida dos \\ Barrageiros, 19274-000, Rosana, SP, Brasil. \\ ${ }^{b}$ Instituto Tecnológico Metropolitano (ITM), Departamento de Ingeniería de Diseño Industrial, \\ Medellín, Colombia. \\ ${ }^{c}$ Centro Universitário Antônio Eufrásio de Toledo, Departamento de Engenharia e Arquitetura, Praça \\ Raul Furquim, 19030-430, Presidente Prudente, SP, Brasil. \\ ${ }^{d}$ Universidade Estadual de Maringá (UEM), Departamento de Meio Ambiente, Campus de Umuarama, \\ Avenida Ângelo Moreira da Fonseca, 87506-370, Umuarama, PR, Brasil. \\ eUniversidade Estadual Paulista (UNESP), Faculdade de Ciência e Tecnologia, Departamento de \\ Física, Campus de Presidente Prudente, Rua Roberto Simonsen, 19060-900, Presidente Prudente, SP, \\ Brasil.
}

Received: January 13, 2021; Revised: March 02, 2021; Accepted: June 16, 2021

\begin{abstract}
This paper investigated the formation of crosslinks in natural rubber compounds in the vulcanization systems: conventional (CV), semi-efficient (SEV), and efficient (EV), processed with three types of accelerators: MBTS (dibenzothiazole disulfide), TMTD (tetramethylthiuram disulfide) and CBS (n-cyclohexyl 2-benzothiazole sulfenamide). The cross-linked densities were determined by organic solvent swelling, dynamic mechanical analysis (DMA), stress $v s$ strain, and low-field nuclear magnetic resonance, the latter being the reference technique for comparison with the other results. It was found that the choice of accelerator type influences the processing time and the cross-linked density of the vulcanizate. The four techniques showed close values of cross-linked density for natural rubber compounds, demonstrating that the analytical techniques studied can be applied to determine crosslinked density.
\end{abstract}

Keywords: Natural rubber, cross-linked density, Flory-Rehner, Mooney-Rivlin, NMR.

\section{Introduction}

Natural rubber (NR) compounds can be cross-linked by sulfur (vulcanization), peroxides (cure), or sulfur donor accelerators, such as tetramethylthiuram (TMTD). The most used curing agent in the rubber industry is sulfur ${ }^{1,2}$, because it offers advantages such as low cost, good compatibility with other additives, and also the predictable properties of vulcanized rubber ${ }^{3,4}$. The degree of cross-linked density or amount of cross-linked per material volume is associated with the number of sulfur atoms bonded between two carbon atoms of two adjacent chains in the polymer structure. These bonds can be of the mono-, di- and polysulfide types ${ }^{5}$ and are predominant according to the vulcanization system (conventional, semi-efficient, and efficient) used ${ }^{6}$. Cross-linked density can be determined by several methods ${ }^{7}$ including balance swelling using an organic solvent. Furthermore, they can also be calculated using the Flory-Rehner equation ${ }^{8,9}$, nuclear magnetic resonance ${ }^{10}$, dynamic mechanical analysis $(\mathrm{DMA})^{11}$, and stress $v s$ strain using the Mooney-Rivlin

*e-mail: renivaldo.santos@unesp.br method $^{12-14}$. The accelerator used in the curing process must have adequate safety time and reaction rate that is compatible with the vulcanization process. It must additionally have adequate vulcanization time and must assist in obtaining the desired final properties of the rubber compound ${ }^{15-17}$. Aside from the choice of the vulcanization system and the characteristics of the accelerator, it is further possible to improve the chemical resistance as regards the degradation and the mechanical properties of the compound with the incorporation of fillers ${ }^{18,19}$. Currently, several studies are being carried out with elastomers - particularly the innovation of formulations ${ }^{20,21}$, such as adding fillers ${ }^{22}$, various crosslinking systems $\mathrm{s}^{23-25}$ and finding new applications ${ }^{26}$. Several methodologies are also being developed to determine cross-linked densities ${ }^{27,28}$ and their thermal ${ }^{29,30}$ and mechanical behavior ${ }^{31}$. Honorato et al..$^{32}$ investigated vulcanized NR compounds using various combinations of accelerators (TMTD / MBT / and Sulfenamide) in an EV curing system. Among the curing systems used, those that contain the highest amount of free sulfur seemingly showed the best mechanical 
performance, before and after aging. The composition with the least number of crosslinks demonstrated superior performance, in relation to the dynamic properties after aging. Howse ${ }^{33}$ determined the amount and distribution of chemical crosslinks in both unaged and aged NR using different TMTD compositions by means of rheometry, hardness, dynamic mechanical properties, stress-strain (Mooney-Rivlin), equilibrium solvent swelling (Flory-Rhener), and low-field nuclear magnetic resonance (NMR) using the double quantum technique (DQ). The degree of crosslinking increased proportionally with TMTD concentration and the reaction rate of three TMTD molecules for crosslinking formation was maintained.

Given the above, it is evident how important it is to study cross-linked density, as well as the techniques used to determine the degree of crosslinking in rubber compounds. This paper thereby aims to compare the techniques used to determine the cross-linked densities of natural rubber compounds in conventional, semi-efficient, and efficient vulcanization systems using three types of accelerators. The four techniques compared in this work for determining cross-linked densities were swelling in organic solvent using the Flory-Rehner equation, dynamic mechanical analysis, stress vs strain using the Mooney-Rivlin equation, and nuclear magnetic resonance by hydrogen in low field.

\section{Experimental Process}

\subsection{Materials}

The materials used in this study were: Natural rubber (Brazilian light crepe, DLP Indústria e Comércio de Borrachas e Artefatos Ltda-ME, Brazil), zinc oxide (99.8\%, PA, neon), stearic acid (95\%, PA, Scientific Exotic), sulfur (99.5\% Scientific Exotic), accelerators (MasterBor Indústria e Comércio de Produtos Químicos LTDA, São Paulo, Brazil): dibenzothiazole disulfide (MBTS), tetramethyltiuram disulfide (TMTD), n-cyclohexyl 2-benzothiazole sulfenamide (CBS). All reagents were both used and purchased without any treatment.

\subsection{Preparation of rubber compounds}

The rubber compounds were made from formulations based on the accelerator/sulfur ratio. Plasticizer oil, antioxidants, fillers, or binary accelerators were not added to avoid affecting the results. Three compounds were prepared for each type of accelerator in each vulcanization system (CV, SEV, and EV). The different compositions are shown in Table 1. An open roller mixer with a friction ratio of 1:1.25 according to ASTM D3182 34 was used.

The compounds obtained were then subjected to rheometric tests (ASTM D2084-17) ${ }^{35}$ using an oscillating disk rheometer (Team Equipment) and a $1^{\circ}$ arc at a temperature of $150^{\circ} \mathrm{C}$. The rheometric parameters determined were: $\mathrm{M}_{\mathrm{L}}$ (minimum torque), $\mathrm{M}_{\mathrm{H}}$ (maximum torque), $\mathrm{ts}_{1}$ (scorch time), $\mathrm{t}_{90}$ (optimum cure time) obtained from Equation 1, and CRI (cure rate index) obtained from Equation 2.

$t_{90}=\left(M_{H}-M_{L}\right) \times 0.9+M_{L}$

$C R I=\frac{100}{t_{90}-t_{s 1}}$

where:

CRI: cure rate index $\left(\mathrm{min}^{-1}\right)$;

$\mathrm{t}_{90}:$ optimal cure time $(\mathrm{min})$;

$\mathrm{ts}_{1}$ : scorch time (min).

The molding of the NR compounds was formed by compression in a hydraulic press with heating at a temperature of $150{ }^{\circ} \mathrm{C}$, under a pressure of $210 \mathrm{kgf} \mathrm{cm}^{-2}$ in a mold measuring $150 \times 150 \times 2 \mathrm{~mm}$.

\subsection{Methodology}

\subsubsection{Cross-linked density by swelling in an organic solvent (Flory-Rehner)}

The determination of the cross-linked density of the compounds was obtained according to the ASTM D297-15(2019) standard ${ }^{36}$ using ethyl alcohol with a density of $0.79 \mathrm{~g} \mathrm{~cm}^{-3}$ and calculated using Equation 3 .

$$
\rho=\frac{\rho_{L} \cdot m_{A}}{m_{A}-m_{B}}
$$

Where:

$\rho=$ sample density $\left(\mathrm{g} \mathrm{cm}^{-3}\right)$;

$\rho_{L}=$ ethanol density at analysis temperature $\left(\mathrm{g} \mathrm{cm}^{-3}\right)$;

$\mathrm{m}_{\mathrm{A}}=$ mass of the wireless sample in air $(\mathrm{g})$;

$\mathrm{m}_{\mathrm{B}}=$ mass of the wireless sample in liquid $(\mathrm{g})$.

Table 1. Formulations and vulcanization properties for rubber compounds produced with various accelerators.

\begin{tabular}{|c|c|c|c|c|c|c|c|c|c|}
\hline \multirow{2}{*}{ MATERIALS } & \multicolumn{3}{|c|}{ CV (phr) } & \multicolumn{3}{|c|}{ SEV (phr) } & \multicolumn{3}{|c|}{ EV (phr) } \\
\hline & CV1 & CV2 & $\mathrm{CV} 3$ & SEV1 & SEV2 & SEV3 & EV1 & EV2 & EV3 \\
\hline Natural rubber & 100 & 100 & 100 & 100 & 100 & 100 & 100 & 100 & 100 \\
\hline Zinc oxide & 4.0 & 4.0 & 4.0 & 4.0 & 4.0 & 4.0 & 4.0 & 4.0 & 4.0 \\
\hline Stearic acid & 2.0 & 2.0 & 2.0 & 2.0 & 2.0 & 2.0 & 2.0 & 2.0 & 2.0 \\
\hline Sulfur & 2.0 & 2.0 & 2.0 & 1.5 & 1.5 & 1.5 & 0.8 & 0.8 & 0.8 \\
\hline MBTS $^{a}$ & 0.4 & --- & --- & 1.1 & --- & --- & 2.0 & --- & --- \\
\hline TMTD $^{\mathrm{b}}$ & --- & 0.4 & --- & --- & 1.1 & --- & --- & 2.0 & --- \\
\hline $\mathrm{CBS}^{\mathrm{c}}$ & --- & --- & 0.4 & --- & --- & 1.1 & --- & --- & 2.0 \\
\hline Ratio used: Accelerator/Sulfur & & 0.2 & & & 0.7 & & & 2.5 & \\
\hline Ratio range: Accelerator/Sulfur ${ }^{82}$ & & $0.1-0.6$ & & & $0.7-2.5$ & & & $2.5-12$ & \\
\hline
\end{tabular}

abenzothiazole disulfide. ${ }^{b}$ tetramethyltiuram disulfide. ${ }^{c}$-cyclohexyl 2-benzothiazole sulfenamide. 
The samples were weighed to a mass of approximately $0.25 \pm 0.05 \mathrm{~g}$ and immersed in toluene in a dark environment for 5 days until equilibrium was reached. The samples were then removed, dried to remove excess solvent, and weighed. The samples were then placed in the oven at a temperature of $80^{\circ} \mathrm{C}$ for 24 hours and weighed. These mass values were used to determine the cross-linked density using Equation 4 developed by Flory-Rehner ${ }^{8,9}$. The values used for the molar volume of toluene $\left(\mathrm{V}_{0}\right)$ and for the Flory-Huggins interaction parameter $(\chi)$ were $106.4 \mathrm{~cm}^{3} \mathrm{~mol}^{-1}$ and 0.39 , respectively ${ }^{37}$.

$$
v=\frac{-\left(\ln \left(1-V_{B}\right)+V_{B}+\chi \cdot\left(V_{B}\right)^{2}\right)}{\left(\rho_{B}\right) \cdot\left(V_{0}\right) \cdot\left(V_{B}^{\frac{1}{3}}-\frac{V_{B}}{2}\right)}
$$

Where:

$v$ : Cross-linked density $\left(\mathrm{mol} \mathrm{cm}^{-3}\right)$;

$\chi$ : polymer-solvent interaction parameter (Flory parameter); $\rho_{\mathrm{B}}$ : rubber density;

$\mathrm{V}_{0}$ : molar volume of the solvent;

$\mathrm{V}_{\mathrm{B}}$ : rubber volume fraction of the swollen form, determined from the increase in weight by swelling.

\subsubsection{Cross-linked density by dynamic mechanical analysis (DMA)}

The DMA tests were performed on a Netzsch model DMTA $242 \mathrm{C}$, in traction mode with a frequency of $3 \mathrm{~Hz}$, at a heating rate of $5^{\circ} \mathrm{C} \mathrm{min}^{-1}$ and a temperature range of $-100{ }^{\circ} \mathrm{C}$ to $150^{\circ} \mathrm{C}$, in test specimens measuring $10 \times 5 \times 0.25 \mathrm{~mm}$. The cross-linked density was determined with the values of the storage module (E') obtained in the DMA test at a temperature of approximately $25 \pm 2{ }^{\circ} \mathrm{C}$ (room temperature) and calculated using Equation $5^{38,39,40 \text { : }}$

$\eta=\frac{E^{\prime}}{6 \cdot R \cdot T}$

where:

$\eta=$ cross-linked density $\left(\mathrm{mol} \mathrm{cm} \mathrm{cm}^{-3}\right)$;

$E^{\prime}=$ elastic storage modulus of the polymer;

$\mathrm{R}=$ universal gas constant $\left(\mathrm{J} \mathrm{mol}^{-1} \mathrm{~K}^{-1}\right)$;

$\mathrm{T}=$ absolute temperature $(\mathrm{K})$.

\subsubsection{Cross-linked density by the Mooney-Rivlin method}

Stress $v s$ strain tests were performed in an Instron traction testing machine at a speed of $50 \mathrm{~mm} \mathrm{~min}^{-1}$ with a $1,000 \mathrm{~N}$ load cell and an internal strain transducer. Quintuplets of test specimens cut into a C-binder format were used to perform the mechanical testing.

The evaluation of the cross-linked density of rubber compounds was based on the Mooney-Rivlin equation ${ }^{41}$, which has been widely used ${ }^{42}$ to correlate the behavior of the network deformation with the crosslinking properties of the polymeric network ${ }^{43}$. This theory is derived from the elastic deformation energy in ideal rubbers ${ }^{44}$. The Mooney-Rivlin theory works well at low to moderate stress levels ${ }^{45}$ and the general expression is shown in Equation $6^{46}$ :

$\frac{\sigma}{\left(\lambda-\lambda^{-2}\right)}=2 . C_{1}+\frac{2 . C_{2}}{\lambda}$

where:

$\sigma=$ actual stress calculated from the stress $\mathrm{x}$ strain curve (MPa);

$\lambda=$ elongation rate;

$\mathrm{C}_{1}=$ parameter related to network structures;

$\mathrm{C}_{2}=$ parameter related to intermolecular forces.

Equation 7 shows the relationship between the cross-linked density obtained by physical means $(n)$ and the constant $\mathrm{C}_{1}$ to estimate the cross-linked density of the vulcanized rubber ${ }^{47}$ :

$\eta=\frac{2 \cdot C_{1}}{R \cdot T}$

where:

$\eta=$ cross-linked density $\left(\mathrm{mol} \mathrm{cm}^{-3}\right)$;

$\mathrm{R}=$ universal gas constant;

$\mathrm{T}=$ absolute temperature $(\mathrm{K})$.

Equation 7 was used to accurately determine the cross-linked density at deformations in the uniaxial direction between 30 to $150 \%\left(\lambda^{-1} \approx 0.4-0.7\right)^{48,49}$.

\subsubsection{Low-field nuclear magnetic resonance cross-linked density using hydrogen}

NMR measurements were performed on a Bruker Mini-spec NMR spectrometer at a frequency of $20 \mathrm{MHz}$ for ${ }^{1} \mathrm{H}$ under $40{ }^{\circ} \mathrm{C}$. For the determination of double quantum (DQ), the conditions were: Pulses of $90^{\circ}$ at $3.1 \mu \mathrm{s}$, pulses of $180^{\circ}$ at $6 \mu$ s and time between scans of $2 \mathrm{~s}$ with the number of scans being equal to 32 . The double quantum ${ }^{1} \mathrm{H}\left(\mathrm{DQ}^{1} \mathrm{H}\right)$ or multiple-quantum ${ }^{1} \mathrm{H}\left(\mathrm{MQ}^{1} \mathrm{H}\right)$ is considered one of the most versatile, robust, and non-invasive NMR analysis techniques. This technique provides a reliable estimate of the cross-linked regions and their distribution, characterized by the representation of a residual dipolar coupling $(\mathrm{RDC})^{50,51}$. The average intensity of the RDC is inversely related to the average molecular mass between dynamically restricted regions and is thus directly related to the cross-linked density in the polymer network ${ }^{52,53}$.

\section{Results and Discussion}

\subsection{Rheometry}

The minimum torque values $\left(\mathrm{M}_{\mathrm{L}}\right)$ are obtained in the pre-cure phase $\left(t_{\mathrm{S} 1}\right)$ where the NR compounds are not yet vulcanized. The $M_{L}$ values are associated with the viscosity of the compound that depends on the degree of processability of the materials that compose $\mathrm{it}^{54}$. The values of maximum torque $\left(\mathrm{M}_{\mathrm{H}}\right)$ for compounds without fillers depend on the degree of crosslinking ${ }^{55,56}$. The curing characteristic is shown in Table 2 based on the NR rheometric parameters in their respective crosslinking systems. 
Table 2. Rheometric parameters of NR compounds vulcanized and accelerated by: MBTS, TMTD and CBS in their respective crosslinking systems.

\begin{tabular}{|c|c|c|c|c|c|c|c|c|}
\hline \multicolumn{2}{|c|}{ Crosslinking systems } & \multirow{2}{*}{ Accelerators } & \multirow{2}{*}{$\frac{\mathrm{M}_{\mathrm{L}}}{(\mathrm{dN} \cdot \mathrm{m})}$} & \multirow{2}{*}{$\frac{\mathrm{M}_{\mathrm{H}}}{\mathrm{(dN} \cdot \mathrm{m})}$} & \multirow{2}{*}{$\frac{\Delta \mathrm{M}}{(\mathrm{dN} \cdot \mathrm{m})}$} & \multirow{2}{*}{$\frac{\mathrm{ts}_{1}}{(\mathrm{~min})}$} & \multirow{2}{*}{$\frac{\mathrm{t}_{90}}{(\mathrm{~min})}$} & \multirow{2}{*}{$\frac{\text { CRI }}{\left(\mathrm{min}^{-1}\right)}$} \\
\hline & & & & & & & & \\
\hline \multirow{3}{*}{$\mathrm{CV}$} & $\mathrm{CV}_{1}$ & MBTS & 0.95 & 12.03 & 11.08 & 4.02 & 11.45 & 13.49 \\
\hline & $\mathrm{CV}_{2}$ & TMTD & 0.89 & 19.75 & 18.86 & 3.32 & 4.82 & 66.33 \\
\hline & $\mathrm{CV}_{3}$ & CBS & 0.99 & 17.27 & 16.28 & 4.62 & 10.35 & 17.48 \\
\hline \multirow{3}{*}{ SEV } & $\mathrm{SEV}_{1}$ & MBTS & 1.00 & 14.75 & 13.75 & 5.07 & 9.15 & 24.55 \\
\hline & $\mathrm{SEV}_{2}$ & TMTD & 0.87 & 19.92 & 19.05 & 3.75 & 4.65 & 110.31 \\
\hline & $\mathrm{SEV}_{3}$ & CBS & 0.84 & 18.92 & 18.08 & 5.25 & 7.65 & 41.83 \\
\hline \multirow{3}{*}{ EV } & $\mathrm{EV}_{1}$ & MBTS & 0.79 & 11.56 & 10.77 & 6.58 & 9.90 & 30.05 \\
\hline & $\mathrm{EV}_{2}$ & TMTD & 0.93 & 18.07 & 17.14 & 3.83 & 5.57 & 58.36 \\
\hline & $\mathrm{EV}_{3}$ & CBS & 0.79 & 15.17 & 14.38 & 6.12 & 8.17 & 49.38 \\
\hline
\end{tabular}

The systems vulcanized with TMTD showed higher values of maximum torque and thus a higher degree of crosslinking. This behavior is due to the fact that this accelerator is a sulfur donor, able to donate up to $13 \%$ sulfur from its own structure ${ }^{57}$.

The semi-efficient vulcanization system (SEV) has a medium sulfur quantity when compared to the conventional system $(\mathrm{CV})$ with a regular sulfur quantity and the efficient system $(\mathrm{EV})$ with a low sulfur quantity ${ }^{58,59}$. The difference between the maximum and minimum torques $(\Delta \mathrm{M})$ indicates the degree of crosslinking in the polymer matrix. As can be seen in Table 2, the compounds with TMTD accelerator were those that exhibited the highest degree of reinforcement ${ }^{60,61}$. The optimal cure time values were lower for TMTD, which also affected the CRI due to its sulfur donor character ${ }^{62}$.

\subsection{Stress vs strain}

Figure 1 shows the curves obtained in the stress vs strain tests. Materials vulcanized with TMTD tend to produce short monosulfide bonds, which are more rigid and thus more susceptible to breakage ${ }^{63,64}$. MBTS compounds showed greater elasticity due to longer crosslinks compared to polysulfide and disulfide types, which are more elastic and flexible and therefore promote greater elongation to failure ${ }^{65}$. Table 3 shows the stress $v s$ strain data. The Semi-Efficient system exhibited the best stress-strain for the three types of accelerators. In this system, the ratio of sulfur to accelerator is close to 1 , likely forming lattices with a predominance of polysulfide and disulfide bonds, resulting in superior stress-strain ${ }^{66}$.

\subsection{Mechanical dynamic analysis (DMA)}

The all-natural rubber compounds had storage modules close to $1,000 \mathrm{MPa}$ at a temperature of $-100{ }^{\circ} \mathrm{C}$ in their respective crosslinking systems. These values are related to the limitations on the relative movements of the polymer chains attributed to the glassy state of the rubber. For values above the glass transition temperature, between $-60^{\circ} \mathrm{C}$ to $-40^{\circ} \mathrm{C}$, all compounds showed an abrupt reduction in the storage module due to the movement of the chains, particularly the longest polymer chains, and the dissipation of mechanical energy attributed to the relaxation of the said chains. The curves of the storage module (E') are shown in Figure 2.
Table 3. Data obtained from the stress versus strain tests of vulcanized and accelerated NR compounds by: MBTS, TMTD and CBS in their respective crosslinking systems.

\begin{tabular}{cccc}
\hline \multirow{3}{*}{ Accelerator } & $\begin{array}{c}\text { Crosslinking } \\
\text { System }\end{array}$ & $\begin{array}{c}\text { Maximum } \\
\text { stress }\end{array}$ & $\begin{array}{c}\text { Maximum } \\
\text { strain }\end{array}$ \\
\cline { 2 - 4 } & CV & $14.6 \pm 0.6$ & $1241.7 \pm 6.6$ \\
\hline \multirow{3}{*}{ MBTS } & SEV & $16.0 \pm 1.5$ & $1170.0 \pm 19.5$ \\
\cline { 2 - 4 } & EV & $14.4 \pm 2.2$ & $1291.7 \pm 27.3$ \\
\hline \multirow{3}{*}{ TMTD } & $\mathrm{CV}$ & $19.2 \pm 1.7$ & $1136.7 \pm 27.7$ \\
\cline { 2 - 4 } & $\mathrm{SEV}$ & $21.7 \pm 3.9$ & $1100.0 \pm 35.3$ \\
\cline { 2 - 4 } & $\mathrm{EV}$ & $17.4 \pm 2.1$ & $1051.7 \pm 28.1$ \\
\hline \multirow{3}{*}{ CBS } & $\mathrm{CV}$ & $17.4 \pm 1.5$ & $1140.0 \pm 28.0$ \\
\cline { 2 - 4 } & $\mathrm{SEV}$ & $21.0 \pm 3.2$ & $1325.0 \pm 22.7$ \\
\cline { 2 - 4 } & $\mathrm{EV}$ & $17.2 \pm 2.3$ & $1128.4 \pm 30.7$ \\
\hline
\end{tabular}

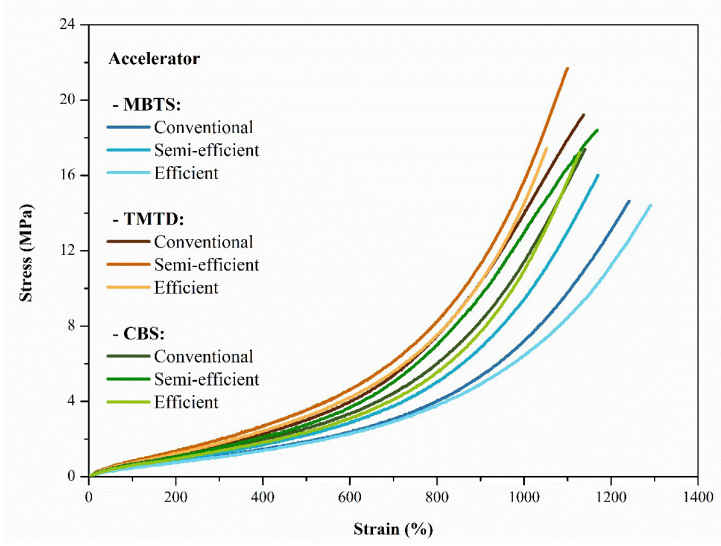

Figure 1. Stress vs. strain curves of NR compounds vulcanized and accelerated by: MBTS, TMTD and CBS in their respective vulcanization systems.

The curves of Tan $\delta$ as a function of temperature are shown in Figure 3. It further illustrates the relaxation of the chains and the maximum dissipation of the system energy ${ }^{67}$. For all compounds, this event occurs with greater intensity at the temperature of around $-40^{\circ} \mathrm{C}$, as shown by the peaks of the Tan $\delta$ curves. 


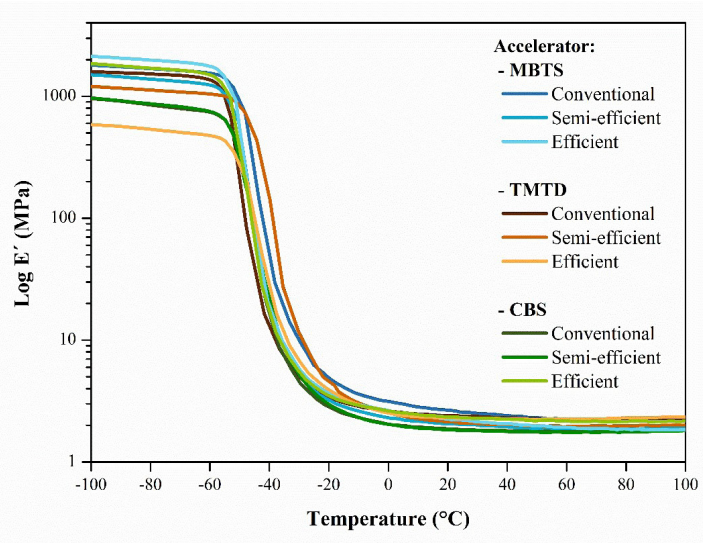

Figure 2. Storage module curves (E') of NR compounds vulcanized and accelerated by: MBTS, TMTD and CBS in their respective vulcanization systems.

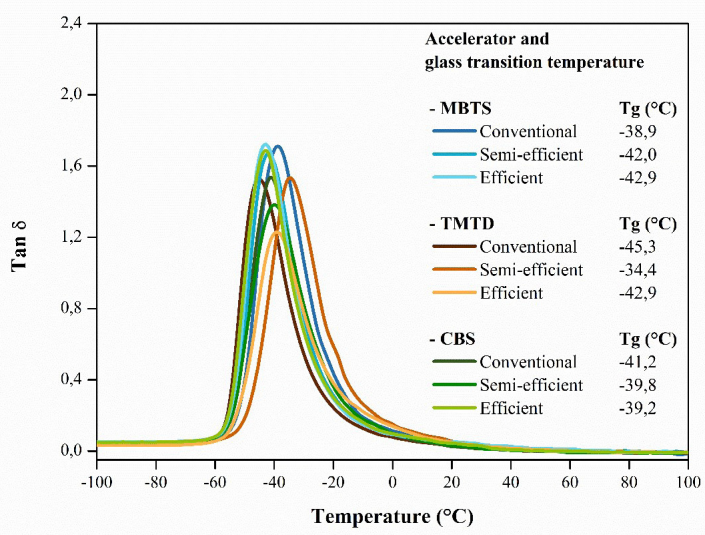

Figure 3. Delta tangent curves (Tan $\delta$ ) of NR compounds vulcanized and accelerated by: MBTS, TMTD and CBS in their respective crosslinking systems.

\subsection{Cross-linked density with NMR}

Analysis of the NMR results has shown that elastomeric networks are far from ideal, so it is important to consider the spatial distribution of crosslinks ${ }^{68,69}$. Figures 4, 5, 6 illustrate the accumulation of magnetization for NR compounds in their respective crosslinking systems, obtained from normalizing the double quantum intensity $\left(\mathrm{I}_{\mathrm{DQ}}\right)$.

The accumulation of magnetization represents only chemical crosslinks, and the higher the normalized $\mathrm{I}_{\mathrm{DQ}}$ intensity of the accumulation curve, the greater the number of crosslinks present $^{70}$. In Figure 4, the conventional MBTS accelerator system presents more crosslinks in relation to the semi-efficient and efficient systems. In Figure 5, the semi-efficient and efficient TMTD accelerator systems show the same number of crosslinks.

Figure 6 also shows the magnetization accumulation curves for the semi-efficient and efficient CBS accelerator systems, which are virtually the same and have the same number of crosslinks. Figure 7 shows the distributions of average molecular weight $(1 / 2 \mathrm{Mc})$ associated with chain size and crosslinks present.

The mechanical properties of vulcanized elastomers are influenced by the distribution and heterogeneity of crosslinks

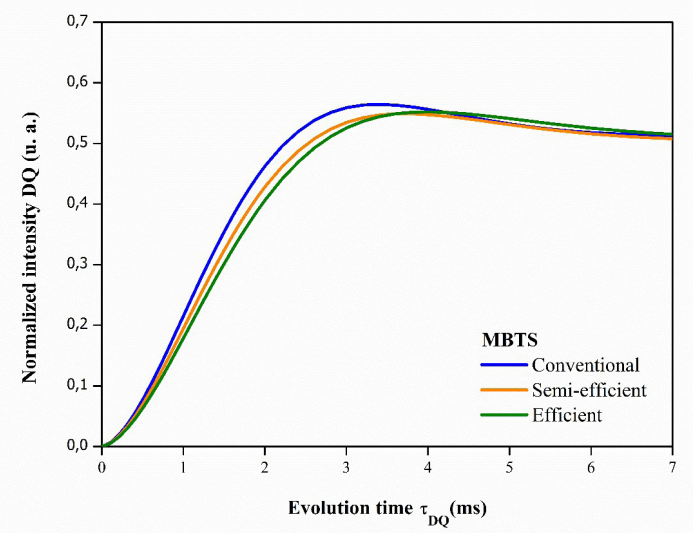

Figure 4. Normalized magnetization accumulation curves for vulcanized NR compounds and those accelerated by MBTS in their respective crosslinking systems.

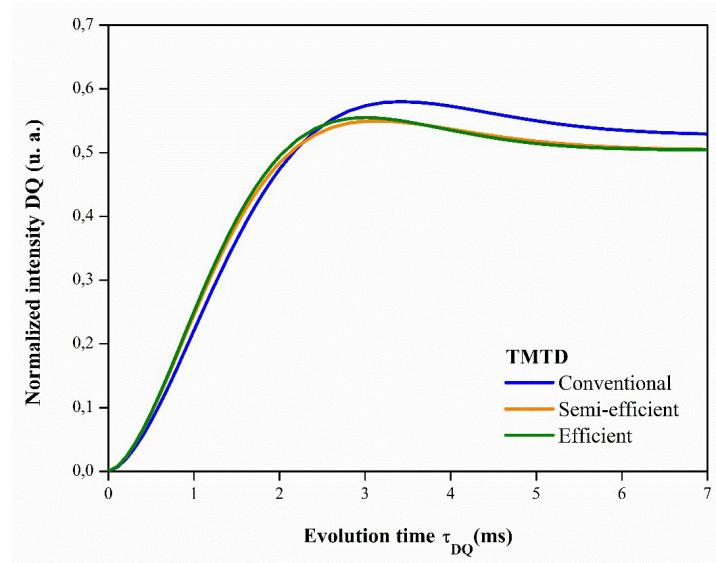

Figure 5. Normalized magnetization accumulation curves for NR compounds vulcanized and accelerated by TMTD in their respective crosslinking systems.

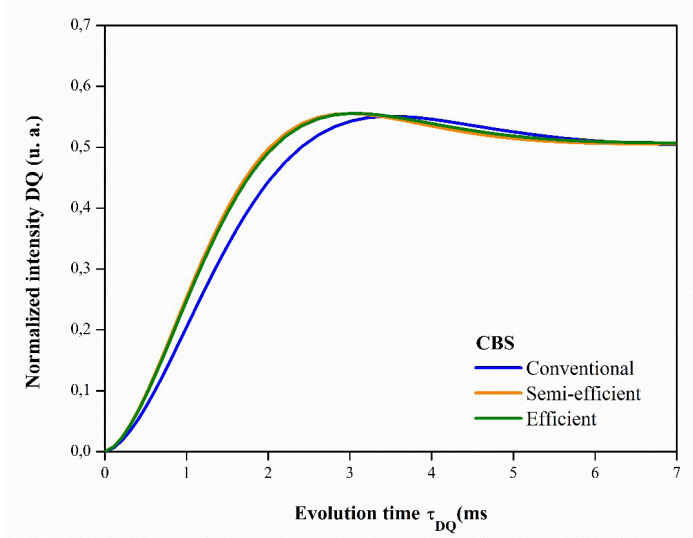

Figure 6. Normalized magnetization accumulation curves for vulcanized NR compounds and those accelerated by MBTS in their respective crosslinking systems.

in the polymeric network ${ }^{71}$. It can be observed that the SEV and EV vulcanization systems had chains with closer molecular weights and therefore with a more homogeneous distribution, except for the cross-linked compounds in the 
Table 4. Cross-linked densities of vulcanized NR compounds determined by the Swelling, DMA, Stress x Strain and ${ }^{1} \mathrm{H}$ NMR techniques in respective crosslinking systems.

\begin{tabular}{|c|c|c|c|c|c|}
\hline \multirow[t]{2}{*}{ Accelerators } & \multirow[t]{2}{*}{$\begin{array}{l}\text { Crosslinking } \\
\text { systems }\end{array}$} & $\begin{array}{c}\text { Swelling } \\
\text { cross-linked density } \\
\text { by Flory Rehner }\end{array}$ & $\begin{array}{c}\text { Cross-linked density } \\
\text { by DMA }\end{array}$ & $\begin{array}{l}\text { Cross-linked density } \\
\text { by Mooney Rivlin }\end{array}$ & $\begin{array}{c}\text { Cross-linked density } \\
\text { by }{ }^{1} \mathrm{H} \text { NMR }\end{array}$ \\
\hline & & $\left(10^{-4} \mathrm{~mol} \mathrm{~cm}^{-3}\right)$ & $\left(10^{-4} \mathrm{~mol} \mathrm{~cm}^{-3}\right)$ & $\left(10^{-4} \mathrm{~mol} \mathrm{~cm}^{-3}\right)$ & $\left(10^{-4} \mathrm{~mol} \mathrm{~cm}^{-3}\right)$ \\
\hline \multirow{3}{*}{ MBTS } & CV1 & $1.36 \pm 0.01$ & $1.74 \pm 0.03$ & $1.97 \pm 0.02$ & $1.81 \pm 0.01$ \\
\hline & SEV1 & $1.20 \pm 0.02$ & $1.37 \pm 0.02$ & $1.93 \pm 0.01$ & $1.70 \pm 0.05$ \\
\hline & EV1 & $0.86 \pm 0.01$ & $1.49 \pm 0.02$ & $1.44 \pm 0.01$ & $1.56 \pm 0.01$ \\
\hline \multirow{3}{*}{ TMTD } & CV2 & $1.29 \pm 0.01$ & $1.59 \pm 0.02$ & $3.10 \pm 0.02$ & $1.78 \pm 0.01$ \\
\hline & SEV2 & $1.28 \pm 0.01$ & $1.41 \pm 0.03$ & $3.30 \pm 0.04$ & $2.07 \pm 0.01$ \\
\hline & EV2 & $1.40 \pm 0.03$ & $1.53 \pm 0.01$ & $2.84 \pm 0.04$ & $2.01 \pm 0.01$ \\
\hline \multirow{3}{*}{ CBS } & CV3 & $1.33 \pm 0.01$ & $1.25 \pm 0.01$ & $2.73 \pm 0.02$ & $1.73 \pm 0.01$ \\
\hline & SEV3 & $1.42 \pm 0.01$ & $1.23 \pm 0.03$ & $2.81 \pm 0.02$ & $2.02 \pm 0.01$ \\
\hline & EV3 & $1.35 \pm 0.01$ & $1.54 \pm 0.02$ & $2.32 \pm 0.03$ & $1.97 \pm 0.01$ \\
\hline
\end{tabular}

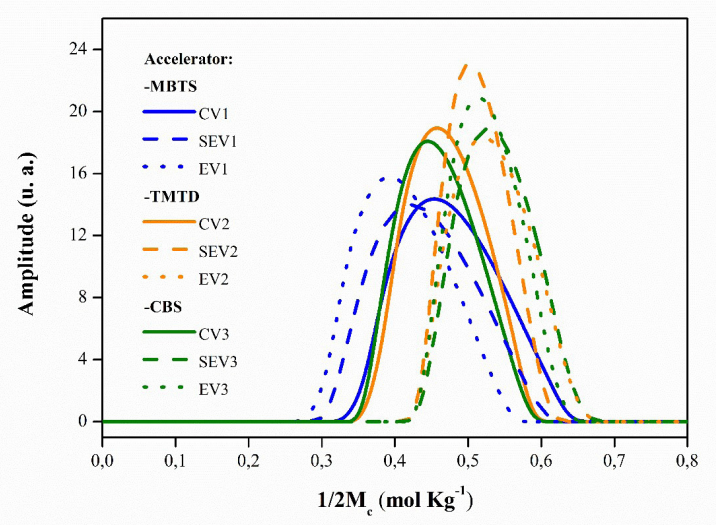

Figure 7. Distribution curves of the average molecular weight of the NR compounds vulcanized and accelerated by: MBTS, TMTD and CBS in their respective crosslinking systems.

presence of MBTS. As the amount of accelerator increased and the amount of sulfur decreased, the distribution of the average molecular weight of the polymer chains shifted to higher values and with more homogeneity.

\subsection{Comparison of cross-linked densities of NR compounds as determined by swelling, $D M A$, stress vs strain, and NMR techniques}

The results of the cross-linked densities obtained by the Swelling, DMA, Stress x Strain, and ${ }^{1} \mathrm{H}$ NMR techniques are on the order of $10^{-4} \mathrm{~mol} \mathrm{~cm}^{-3}$, indicating that the four techniques showed relatively coherent results for determining the cross-linked densities. The results obtained with the four techniques are shown in Table 4.

Therefore, the crosslink density determined by physical means such as DMA, stress $x$ strain (obtained from the elastic regions) and ${ }^{1} \mathrm{H}$ NMR has higher values compared to the solvent swelling.

NMR experiments are done in a relaxed state. While the tests of stress-strain, DMA and swelling correspond to deformations of large amplitude. In Table 4, the results of different techniques are correlated. The values differ slightly between the techniques, due to defects (topological restrictions, entanglements, etc.) acting differently in the different techniques besides the stable cross-links ${ }^{72}$. Furthermore, in determining the crosslink density, each technique uses different nature information of vulcanized rubber. For example, in the hydrogen NMR at low magnetic field the hydrogen protons were studied, being possible to determine the number of each of the different types of non-equivalent protons, as well as obtain similar information regarding the nature of the immediate environment by a simplified dynamic model of network chain characterization $^{73}$. The uniaxial stress-strain test was used to obtain the crosslink density, the data were obtained from the curves in the range of strains between 30 to $150 \%$, with a rate of $50 \mathrm{~mm} \mathrm{~min}^{-1}$ in a quasi-equilibrium deformation system The theories by which this can be done differ mainly in the way in which topological interactions between network chains are taken into account. The network model used was the affine applied in the Mooney-Rivlin equation ${ }^{74}$. The determination of crosslinked densities by dynamic mechanical analysis was determined experimentally by measuring the elastic storage module in the rubber plateau region at room temperature. In this technique, the effects of chain ends, main chain splitting and entangled chain entanglements acting as crosslinking were not taken into account, which can result in a quantitative error in the crosslinking density determinations ${ }^{75}$. An alternative is the analysis of the swelling equilibrium in a suitable solvent, it has been widely used to characterize network structures of elastomeric. The Flory-Rehner equation, based on the elastic response to the osmotic stress of the solvent, directly relates the rubber volume fraction at swelling equilibrium to the average molecular weight between cross-links. Thus, the average molecular weight between the cross-links can be determined in a simple way ${ }^{76}$.

Several works in the literature have shown that increasing the sulfur content favors the crosslinking degree, which in turn increases the cross-linked densities ${ }^{77-79}$. However, as shown in the studies in this paper, only the MBTS met this condition in the CV, SEV, and EV systems when swelling, stress $x$ strain, and NMR were used. So, the exception is the MBTS with EV system when DMA was used.

The NMR results are more sensitive and accurate compared to the other techniques mentioned because it examines the structure of the network at the molecular level and identifies all types of defects that restrict the movement of the polymer chains ${ }^{80}$. When comparing the results in 
Table 4, the results from the NMR technique were those that showed the least variation. Valentin and Saalwachter compared the swelling techniques in solvent and NMR for determining crosslinks and questioned the results obtained by swelling. In their work, they identified possible errors associated with the Flory-Rehner equation in determining the volumetric fraction of the rubber, with the Flory-Huggins parameter for polymer-solvent interaction, and with the applied model of rubber elasticity.

The highest values of crosslinking densities were obtained in the stress-strain tests, as shown in Table 4. Hagen and co-authors showed that the crosslink density depends on the time scale of the method used, which means that there is not sufficient time to disentangle before the direction of deformation is reversed during dynamic mechanical tests. The lowest crosslink densities are obtained from equilibrium swelling data, where all entanglements that are not trapped have enough time to untangle themselves.

The rubbers have complex parameters and properties that are difficult to predict and require further study. Some of these parameters and properties are the length distribution of the main polymer chain, network defects (free ends of the chain, cyclic links, and entanglement of the chains), and limited chain extensibility (applicable in the elastic ranges between 30 to $150 \%$ of the chain length deformation) ${ }^{81}$.

\section{Conclusions}

In this work, we investigated the cross-linked density using different techniques, in three crosslinking systems: conventional, semi-efficient, and efficient in the presence of three accelerators: MBTS, TMTD, and CBS. The solvent swelling tests are the most commonly used by researchers today and their results are unanimously accepted. However, the results showed that the other methods for determining the cross-linked densities are consistent and provide satisfactory results for studying the mechanical properties of natural rubber compounds. Using the NMR technique as a reference, since it is a more accurate method for determining the cross-linked density among the other techniques, the results showed that the stress $v s$ strain and DMA techniques are suitable for estimating the cross-linked density within a small margin of error. The stress $v s$ strain and DMA techniques are simpler and less expensive compared to the NMR technique. Thus, new opportunities are created to measure crosslinks using alternative methods that provide adequate, simple, and rapid tools for studying cross-linked density, in addition to choosing a crosslinking system with accelerators suitable for the desired applications of natural rubber compounds.

\section{Acknowledgments}

The authors would like to thank MasterBor Comércio e Indústria Química LTDA for supplying the accelerators, Centro Universitário Antônio Eufrásio de Toledo for stress vs strain tests, Universidade de São Paulo, São Carlos campus, for the analysis of nuclear magnetic resonance, and Instituto Tecnológico Metropolitano from Colombia for collaborations.

This study was financed in part by the Coordenação de Aperfeiçoamento de Pessoal de Nível Superior - Brasil (CAPES) - Finance Code 001.

\section{References}

1. Hewitt N. Compounding precipitated silica in elastomers: theory and practice. Burlington: Elsevier; 2007.

2. Khang TH, Ariff ZM. Vulcanization kinetics study of natural rubber compounds having different formulation variables. J Therm Anal Calorim. 2012;109(3):1545-53.

3. Brydson JA. Rubber chemistry. London: Applied Science Publishers; 1978. 462 p.

4. Ahsan Q, Mohamad N, Soh TC. Effects of accelerators on the cure characteristics and mechanical properties of natural rubber compounds. Int J Automot Mech Eng. 2015;12:2954.

5. Marković G, Marinović-Cincović M, Samaržija-Jovanović S, Jovanović V, Budinski-Simendić J. Crosslinking of polymers: rubber vulcanization. In: Gutiérrez TJ, editors. Reactive and functional polymers volume two: modification reactions, compatibility and blends. Cham: Springer; 2020. p. 117-34.

6. Yahya YS, Azura AR, Ahmad Z. Effect of curing systems on thermal degradation behaviour of natural rubber (SMR CV 60). J Physiol Sci. 2011;22(2):1-14.

7. Nielsen LE. Cross-linking effect on physical properties of polymers. J Macromol Sci Part C. 1969;3(1):69-103.

8. Flory PJ, Rehner J Jr. Statistical mechanics of cross-linked polymer networks I: rubberlike elasticity. J Chem Phys. 1943;11(11):512-20.

9. Vieyres A, Pérez-Aparicio R, Albouy PA, Sanseau O, Saalwächter $\mathrm{K}$, Long DR, et al. Sulfur-cured natural rubber elastomer networks: correlating cross-link density, chain orientation, and mechanical response by combined techniques. Macromolecules. 2013;46(3):889-99.

10. Valentín JL, Carretero-González J, Mora-Barrantes I, Chassé W, Saalwachter K. Uncertainties in the determination of cross-link density by equilibrium swelling experiments in natural rubber. Macromolecules. 2008;41(13):4717-29.

11. Hagen R, Salmén L, Stenberg B. Effects of the type of crosslink on viscoelastic properties of natural rubber. J Polym Sci B Polym Phys. 1996;34(12):1997-2006.

12. Rivlin RS. Large elastic deformations of isotropic materials IV. Further developments of the general theory. Philos Trans R Soc Lond A. 1948;241(835):379-97.

13. Schlögl S, Trutschel ML, Chassé W, Riess G, Saalwächter K. Entanglement effects in elastomers: macroscopic vs microscopic properties. Macromolecules. 2014;47(9):2759-73.

14. Dzulkifli AI, Said CMS, Han CC. Determination of crosslink concentration by Mooney-Rivlin equation for vulcanized NR/ SBR blend and its influence on mechanical properties. Malays J Anal Sci. 2015;19(6):1309-17.

15. Goyanes S, Lopez CC, Rubiolo GH, Quasso F, Marzocca AJ Thermal properties in cured natural rubber/styrene butadiene rubber blends. Eur Polym J. 2008;44(5):1525-34.

16. Palaty S, Joseph R. Studies on xanthate/dithiocarbamate accelerator combination in NR/BR blends. J Appl Polym Sci. 2007;103(6):3516-20.

17. Aprem AS, Mathew G, Joseph K, Thomas S. A new binary accelerator system for sulphur vulcanization of natural rubber. Kautsch Gummi Kunstst. 1999;52(9):576-82.

18. Wypych G. Handbook of fillers. Toronto: ChemTec Pub; 2010.

19. Akovali G. Handbook of composite fabrication. Shawbury, UK: Rapra Technology Ltd.; 2001.

20. Srewaradachpisal S, Dechwayukul C, Chatpun S, Spontak RJ, Thongruang W. Optimization of rubber formulation for footwear applications using the response surface method. Polymers. 2020;12(9):2032.

21. Rodgers B. Rubber compounding: chemistry and applications. Boca Raton: CRC press; 2015.

22. Rattanasom N, Saowapark TA, Deeprasertkul C. Reinforcement of natural rubber with silica/carbon black hybrid filler. Polym Test. 2007;26(3):369-77. 
23. Lorenz O, Parks CR. The crosslinking efficiency of some vulcanizing agents in natural rubber. J Polym Sci Polym Phys Ed. 1961;50(154):299-312.

24. Hofmann W. Vulcanization and vulcanizing agents. London: Maclaren; 1967.

25. Kruželák J, Hudec I. Vulcanization systems for rubber compounds based on IIR and halogenated IIR: an overview. Rubber Chem Technol. 2018;91(1):167-83.

26. Guo X, Xiang D, Duan G, Mou P. A review of mechanochemistry applications in waste management. J Waste Manag. 2010;30(1):410.

27. Matzen D, Straube E. Mechanical properties of SBR-networks: I. determination of crosslink densities by stress-strain-measurements. Colloid Polym Sci. 1992;270(1):1-8.

28. Coran AY. Vulcanization - part III. Rapid methods for characterizing rubber networks. Rubber Chem Technol. 1964;37(3):668-72.

29. Johns J, Rao V. Thermal stability, morphology, and X-ray diffraction studies of dynamically vulcanized natural rubber/ chitosan blends. J Mater Sci. 2009;44(15):4087-94.

30. Dee PP, Choudhury NR, Dutta NK, editors. Thermal analysis of rubbers and rubbery materials. Shrewsbury: ISmithers Rapra; 2010.

31. Brown R. Physical testing of rubber. Boston: Springer Science \& Business Media; 2006.

32. Honorato LR, Nunes RCR, Cosme JGL, Visconte LLY, Peres ACDC, Costa JM. Effect of the cure system on aging resistance of natural rubber compounds. J Elastomers Plast. 2019;52(5):397409.

33. Howse S, Porter C, Mengistu T, Pazur RJ. Experimental determination of the quantity and distribution of chemical crosslinks in unaged and aged natural rubber, part II: a sulfur donor system. Rubber Chem Technol. 2019;70:263-74.

34. ASTM: American Society for Testing and Materials. Standard ASTM D3182-15 - standard rubber practice - materials, equipment and procedures for mixing standard compounds and preparing standard vulcanized sheets. West Conshohocken: ASTM International; 2015.

35. ASTM: American Society for Testing and Materials. Standard ASTM D2084-17 - standard test method for rubber property - vulcanization using oscillating disk curing meter. West Conshohocken: ASTM International; 2017.

36. ASTM: American Society for Testing and Materials. Standard ASTM D297-15 - standard test methods for rubber products chemical analysis. West Conshohocken: ASTM International; 2019.

37. Sperling LH. Introduction to physical polymer science. Hoboken: Wiley \& Sons; 2005.

38. Khonakdar HA, Morshedian J, Wagenknecht U, Jafari SH. An investigation of chemical crosslinking effect on properties of high-density polyethylene. Polymer. 2003;44(15):4301-9.

39. Chartoff PR, Menczel JD, Dillman SH. Dynamic Mechanical Analysis (DMA). In: Menczel JD, Prime RB, editors. Thermal analysis of polymers: fundamentals and application. Hoboken: Wiley \& Sons; 2009.

40. Menard KP, Menard NR. Dynamic mechanical analysis. Boca Raton: CRC Press; 2020. 280 p.

41. Dzulkifli AI, Said CMS, Han CC. Determination of crosslink concentration by mooney-rivlin equation for vulcanized NR/ SBR blend and its influence on mechanical properties. Malaysian Journal of Analytical Sciences. 2015;19(6):1309-17.

42. Sekkar V, Narayanaswamy K, Scariah KJ, Nair PR, Sastri KS, Ang HG. Evaluation by various experimental approaches of the crosslink density of urethane networks based on hydroxylterminated polybutadiene. J Appl Polym Sci. 2007;103(5):312933.

43. Tanasi P, Santana MH, Carretero-González J, Verdejo R, LópezManchado MA. Thermo-reversible crosslinked natural rubber: a Diels-Alder route for reuse and self-healing properties in elastomers. Polymer. 2019;175:15-24.

44. Yeoh OH. Hyperelastic material models for finite element analysis of rubber. Journal of Natural Rubber Research. 1997;12:142.

45. Xia Z, Patchan M, Maranchi J, Elisseeff J, Trexler M. Determination of crosslinking density of hydrogels prepared from microcrystalline cellulose. J Appl Polym Sci. 2013;127(6):4537-41.

46. Sombatsompop N. Practical use of the Mooney-Rivlin equation for determination of degree of crosslinking of swollen $\mathrm{nr}$ vulcanisates. J Sci Soc. 1998;24(3):199-204.

47. Sombatsompop N. Analysis of cure characteristics on cross-link density and type, and viscoelastic properties of natural rubber. Polym Plast Technol Eng. 1998;37(3):333-49.

48. Bobear WJ. Chain density in rubber networks. Rubber Chem Technol. 1967;40(5):1560-9.

49. Chan BL, Elliott DJ, Holley M, Smith, JF. The influence of curing systems on the properties of natural rubber. J Polym Sci Polym Symp. 1974;48(1):61-86.

50. Colnago LA, Andrade FD. Time domain NMR: fundamentals and applications offline and online. In: Resende RR, editor. Biotechnology applied to agro \& industry. São Paulo: Blucher; 2017.

51. Hernandez M, Valentin JL, Lopez-Manchado, MA, Ezquerra TA. Influence of the vulcanization system on the dynamics and structure of natural rubber: comparative study by means of broadband dielectric spectroscopy and solid-state NMR spectroscopy. Eur Polym J. 2015;68:90-103.

52. Cunha GP. Study of the microstructure and molecular dynamics of Poly (3- (2 ‘'- ethylhexyl) thiophene) (P3EHT) via nuclear magnetic resonance [thesis]. São Paulo: University of Sao Paulo; 2016.

53. Shapiro YE. Progress in Polymer Science Structure and dynamics of hydrogels and organogels: an NMR spectroscopy approach. Prog Polym Sci. 2011;36(9):1184-253.

54. Abd AA. Study the effect of mica as filler in natural rubber properties. Journal of University of Babylon. 2016;24(3):77381.

55. Thulasimani C, Ramesh S, Ramesh K, Salmah H. Fabrication and characterization of natural rubber/Imperata cylindrica cellulose fiber biocomposites. Asia-Pac J Chem Eng. 2015;10(5):716-23.

56. Mottaghi M, Khorasani SN, Esfahany MN, Farzadfar A, Talakesh $\mathrm{MM}$. Comparison of the effect of nano $\mathrm{ZnO}$ and conventional grade $\mathrm{ZnO}$ on the cross-linking densities of $\mathrm{NR} / \mathrm{BR}$ and $\mathrm{NR} /$ SBR blends. J Elastomers Plast. 2012;44(5):443-51.

57. White J, De SK, White JR, Naskar K. Rubber Technologist's Handbook. Shrewsbury: Smithers Rapra; 2001.

58. Bornstein D, Pazur RJ. The sulfur reversion process in natural rubber in terms of crosslink density and crosslink density distribution. Polym Test. 2020;88:106524.

59. Xie ZT, Luo MC, Huang C, Wei LY, Liu YH, Fu X, et al. Effects of graphene oxide on the strain-induced crystallization and mechanical properties of natural rubber crosslinked by different vulcanization systems. Polymer. 2018;151:279-86.

60. Costa HM, Visconte LLY, Nunes RCR, Furtado, CRG. Rice husk ash filled natural rubber III. Role of metal oxides in kinetics of sulfur vulcanization. J Appl Polym Sci. 2003;90(6):1519-31.

61. Ooi ZX, Ismail H, Bakar AA. Curing characteristics, mechanical, morphological, and swelling assessment of liquid epoxidized natural rubber coated oil palm ash reinforced natural rubber composites. Polym Test. 2014;33:145-51.

62. Morton M, editor. Rubber technology. Amsterdam: Springer Netherlands; 1987.

63. Morrison NJ, Porter M. Zinc acelerator complex. Rubber Chemistry and Technology.1984;57:63.

64. Morrison NJ, Porter M. Temperature effects on the stability of intermediates and crosslinks in sulfur vulcanization. Rubber Chem Technol. 1984;57(1):63-85. 
65. Sommer JG. Engineered rubber products: introduction to design, manufacturing and testing. Munich: Carl Hanser Verlag; 2009.

66. Zhao F, Bi W, Zhao S. Influence of crosslink density on mechanical properties of natural rubber vulcanizates. J Macromol Sci Part B. 2011;50(7):1460-9.

67. Lei Z, Xing W, Wu J, Huang G, Wang X, Zhao L. The proper glass transition temperature of amorphous polymers on dynamic mechanical spectra. J Therm Anal Calorim. 2014;116(1):447-53.

68. Besghini D, Mauri M, Simonutti R. Time domain NMR in polymer science: from the laboratory to the industry. Appl Sci. 2019;9(9):1801.

69. Dibbanti MK. Study of polymer cross-link density by time domain NMR spectroscopy [thesis]. Italy: University of MilanoBicocca; 2015.

70. Saalwächter K. Proton multiple-quantum NMR for the study of chain dynamics and structural constraints in polymeric soft materials. Prog Nucl Magn Reson Spectrosc. 2007;51(1):1-35.

71. Schlögl S, Trutschel ML, Chassé W, Letofsky-Papst I, Schaller R, Holzner A, et al. Photo-vulcanization using thiol-ene chemistry: film formation, morphology and network characteristics of UV crosslinked rubber latices. Polymer. 2014;55(22):5584-95.

72. Howse S, Porter C, Mengistu T, Pazur RJ. Experimental determination of the quantity and distribution of chemical crosslinks in unaged and aged natural rubber, part 1: peroxide vulcanization. Polym Test. 2018;70:263-74.

73. Mlynárik V. Introduction to nuclear magnetic resonance. Anal Biochem. 2017;529:4-9.

74. Gronski W, Hoffmann U, Simon G, Wutzler A, Straube E. Structure and density of crosslinks in natural-rubber vulcanizates.
A combined analysis by NMR spectroscopy, mechanical measurements, and rubber-elastic theory. Rubber Chem Technol. 1992;65(1):63-77.

75. Shen J, Lin X, Liu J, Li X. Effects of cross-link density and distribution on static and dynamic properties of chemically cross-linked polymers. Macromolecules. 2018;52(1):121-34.

76. Borges FTP, Papavasiliou G, Teymour F. Characterizing the molecular architecture of hydrogels and crosslinked polymer networks beyond Flory-Rehner: I. theory. Biomacromolecules. 2020;21(12):5104-18.

77 Datta RN. Rubber curing systems. Shawbury: Rapra Technology Ltd.; 2002.

78. Coran AY. Vulcanization A2. In: Erman B, Mark JE, Roland $\mathrm{CM}$, editors. The science and technology of rubber. Waltham: Academic Press (Elsevier); 2005.

79. Bateman L. The chemistry and physics of rubber-like substances. New York: Wiley \& Sons; 1963.

80. Nie S, Ratzsch KF, Grage SL, Keller J, Ulrich AS, LacayoPineda $\mathrm{J}$, et al. Correlation between macroscopic elasticity and chain dynamics of natural rubber during vulcanization as determined by a unique rheo-NMR combination. Macromolecules. 2021;1 00354 .

81. Rehage G. Elastic properties of crosslinked polymers. In: International Symposium on Macromolecules; 1974 Sep 10-14; Aberdeen. Specially invited and selected symposium lectures. Aberdeen: Butterworths; 1974. p. 161-78.

82. Chapman AV. Porter M. Sulphur vulcanization chemistry. In: Roberts $\mathrm{AD}$, editor. Natural rubber science and technology. Oxford: Oxford University Press; 1988. 